\title{
Immunolocalization and Cellular Expression af Key Abc Transporter Proteins and Their Correlation with the Grades and Subtypes of Canine Mammary Tumour
}

\author{
Manoj Kumar ${ }^{1}$, Kuldip Gupta ${ }^{1}$, Naresh Kumar Sood ${ }^{3 *}$ and Amarjit Singh ${ }^{1}$ \\ ${ }^{1}$ Department of Veterinary Pathology, Guru Angad Dev Veterinary and Animal Sciences University, India \\ ${ }^{2}$ Department of Teaching Veterinary Clinical Complex, Guru Angad Dev Veterinary and Animal Sciences University, India
}

Received: 㭗: July 16, 2018; Published: 阱 July 30, 2018

*Corresponding author: Dr. Naresh Kumar Sood, Department of Teaching Veterinary Clinical Complex, Guru Angad Dev Veterinary and Animal Sciences University, College of Veterinary Science, India

\begin{abstract}
Objective: To determine the immunolocalization and cellular expression of adenosine triphosphate-binding cassette (ABC) proteins viz. breast cancer resistance protein (BCRP) and multidrug resistance protein 1 (MDR1) in canine mammary tumour (CMT), as well as to correlate their expression with the histological subtypes and grades of CMT with a view towards therapeutic implications.

Methods: Fifty-three cases of malignant CMT were included in the study. The histological sections taken from archived paraffin blocks were subjected to histopathology and imunohistochemistry for sub-typing, grading, immunolocalization and cellular expression of BCRP and MDR1 and their interrelation.

Results: Both BCRP and MDR1 were mainly immulocalized in cellular membranes and to a lesser extent in the cytoplasm of the cancerous epithelial cells and stromal connective tissue. Carcinosarcomas followed by carcinomas and sarcomas revealed decreasing expression of both BCRP and MDR1 proteins. A positive and an inverse correlation between BCRP and MDR1 expression, respectively was observed with the increasing grade of CMT.

Conclusion: The study implicates the role of ABC transporter proteins in possible chemotherapeutic drug resistance that may vary with the subtype and grade of CMT.
\end{abstract}

Keywords: ABC Transporter Proteins; BCRP; Canine Mammary Tumour; Drug Resistance proteins; MDR1

Abbreviations: BCRP: Breast Cancer Resistance Protein; CMT: Canine Mammary Tumour; EMT: Epithelial to Mesenchymal Transition; MDR1: Multidrug Resistance Protein 1; ABC: Atp-Binding Cassette.

\section{Introduction}

Canine mammary tumour (CMT) is the second most common neoplasm after skin tumours [1-4], and nearly half of them are malignant [3-5]. Their clinicopathological and histopathological features, and hormonal behaviour are similar to the human breast cancer $[3,6]$. In addition, both the species share similar environment, nutrition, age, sex, and reproductive factors that lead to the development and progression of cancer [7]. The recurrence risk of canine mammary gland tumors as well as human breast cancer is very high [8], and $58 \%$ of the affected dogs develop a new tumour after the surgical resection of the first tumour [9]. Therefore, chemotherapy may become imminent against canine mammary cancer in future. However, the cancer chemotherapy is often a failure due to development of single or multiple drug resistance as already faced by medical oncologists. Among multiple factors, ATP-binding cassette $(\mathrm{ABC})$ transporters have been well documented as a cause of drug resistance [10]. The most studied $\mathrm{ABC}$ transporter proteins include breast cancer resistance protein
(BCRP) and multidrug resistance protein 1 (MDR1) [11,12]. However, the role of BCRP and MDR1 in CMT, particularly as to their imunolocalization and their variability in expression with the histologic subtype and grade is rather poorly investigated.

\section{Methods}

\section{Source of Samples}

The present study was conducted on archived tissue samples from 53 cases of malignant CMT available with the Department of Veterinary Pathology, GADVASU, Ludhiana, India.

\section{Histopathology}

The tissue samples from CMT cases were fixed in 10\% neutral buffered formalin, embedded in paraffin wax, sectioned at 4-5 $\mu$ and stained with routine $\mathrm{H} \& \mathrm{E}$ [13]. The CMT were classified and graded following WHO classification $[5,14]$ and its modification thereof [15], following independent examination by two pathologists. 


\section{Immunohistochemical Staining and Its Interpretation}

For immunohistochemistry, 4-5 $\mu$ thick paraffin-embedded tissue sections were cut and mounted on Super frost/Plus, positively charged microscopic slides (Fisher Scientific, USA) and immunohistochemical staining for BCRP and MDR1 was performed by using Imm PACT DAB Peroxidase Substrate Kit (Vector Laboratories, Burlingame CA, USA). The sections were dewaxed and rehydrated by dipping in EZ-AR Common Solution (BioGenex Laboratories Inc., San Ramon, California, USA), by heating at 70 ${ }^{\circ} \mathrm{C}$ for $10 \mathrm{~min}$. in EZ-Retriever System (BioGenex Laboratories Inc., San Ramon, California, USA) and subsequent antigen retrieval was performed by heat using citrate-based EZ-AR 3 Solution (BioGenex Laboratories Inc., San Ramon, California, USA) at $95{ }^{\circ} \mathrm{C}$ for $10 \mathrm{~min}$. followed by Tris EDTA heat induced antigen retrieval at $95{ }^{\circ} \mathrm{C}$ for $10 \mathrm{~min}$. (Tris-6.2g and EDTA-0.75g in $1000 \mathrm{ml}$ of distilled water, $\mathrm{pH}$ 9.0). Following antigen retrieval the sections were allowed to cool and brought to room temperature before being washed three times in PBS (pH 7.2-7.4) for 3 min. each time. Sections were encircled with a hydrophobic pen.

The endogenous peroxidase was quenched with a solution of 3\% $\mathrm{H} 2 \mathrm{O} 2$ in methanol for $15 \mathrm{~min}$. at room temperature in a humid chamber, followed by thrice washing with PBS for 3 min. each. The sections were then incubated with a ready to use $2.5 \%$ normal horse serum (Vector Laboratories, Burlingame CA USA) for 15 $\min$. at room temperature in a humidified chamber. Thereafter, the sections were incubated overnight with Novus Biologicals Colorado, USA primary antibodies i.e. polyclonal BCRP antibody, 1:50 dilution, and monoclonal MDR1 antibody (clone C219), 1:25 dilution at $4^{\circ} \mathrm{C}$ overnight in a humidified chamber in a refrigerator. The sections were then washed three times in PBS for 3 min. each, followed by incubation in Polymer HRP (Vector Laboratories, Burlingame CA, USA) for $30 \mathrm{~min}$ at room temperature in a humidified chamber followed by three washes with PBS for 3 min each. The antigenantibody-peroxidase reaction was developed with a freshly prepared 3,3'-diaminobenzidine (DAB) solution.

Table 1: Evaluation immunohistochemical expression of BCRP and MDR1.

\begin{tabular}{|c|c|c|c|}
\hline $\begin{array}{c}\text { Percentage of positive } \\
\text { cells }\end{array}$ & Points & $\begin{array}{c}\text { Intensity of } \\
\text { reaction }\end{array}$ & Points \\
\hline No positive cells & 0 & No reaction & 0 \\
\hline$<10 \%$ & 1 & $\begin{array}{c}\text { Weak reaction } \\
(+)\end{array}$ & 1 \\
\hline $10-50 \%$ & 2 & $\begin{array}{c}\text { Moderate } \\
\text { reaction (++) }\end{array}$ & 2 \\
\hline $51-80 \%$ & 3 & $\begin{array}{c}\text { Strong reaction } \\
(+++)\end{array}$ & 3 \\
\hline$>80 \%$ & 4 & & \\
\hline
\end{tabular}

Sections were later washed in distilled water for $5 \mathrm{~min}$. and counterstained with Gill's haematoxylin (Merck, Germany) for 30 seconds and washed in running tap water for $5 \mathrm{~min}$. Finally the slides were dehydrated in ascending grades of alcohol, cleared in xylene, mounted in DPX and examined under a microscope (BX 61, Olympus Corporation, Japan). For each antibody, a negative control was run by replacing the primary antibody with PBS buffer. Immunoreactivity of BCRP and MDR1was evaluated using the semiquantitative staining index (SI) score and immunoreactive score (IRS) for BCRP and MDR1, respectively, in which the intensity of the reaction and the proportion of positive cells were considered. The percentage of positive cells was determined on a scale of 0 to 4 , and labelling intensity on a scale of 0 to 3 (Table 1). The SI score for BCRP and IRS for MDR1 was determined by multiplying the percentage of immunoreactive cells and the labelling intensity $[16,17]$.

\section{Statistical Analysis}

The statistical analysis was carried out using SPSS 16.0 software and Spearman's correlation between the SI score and IRS with the grade of CMT was determined.

\section{Results}

On the basis of histological classification of CMT, 26 cases were carcinomas, 20 carcinosarcomas and 7 sarcomas. Carcinomas were further classified into simple carcinoma (6/26), complex carcinoma (17/26), squamous cell carcinoma (2/26) and malignant myoepithelioma (1/26). The twenty cases of carcinosarcomas consisted of varying degree of epithelial, connective tissue and metaplastic components. Whereas, sarcomas comprised of 5 cases of osteosarcoma and one each of hemangiosarcoma and fibrosarcoma. Positive immunoreactivity of BCRP was observed in all the 53 cases of CMT. Diffuse and variable membranous and cytoplasmic immunoreactivity of BCRP was observed in cancerous epithelial cells and stromal connective tissue cells (Figures 1-3). The immunoreactivity of BCRP was also observed in endothelium, blood vessel wall, ductular epithelium and tumor emboli. On the basis of staining intensity, 7 cases revealed weak (+) immunoreactivity, 30 cases moderate $(++)$ immunoreactivity and 16 cases strong (+++) immunoreactivity.

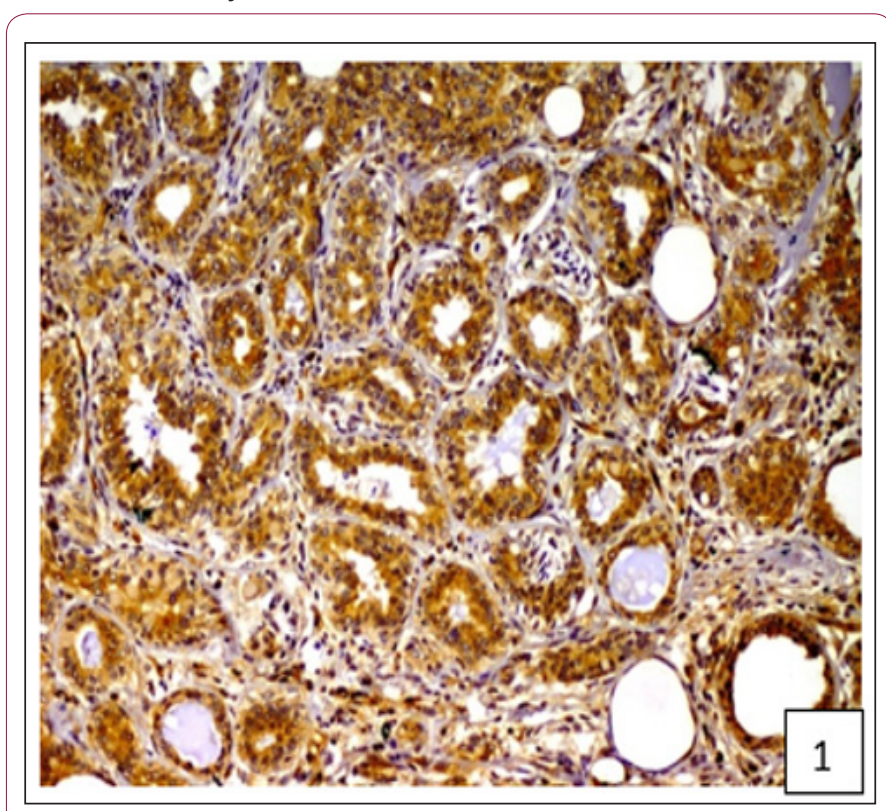

Figure 1: Diffuse and variable membranous and cytoplasmic immunoreactivity of BCRP was observed in cancerous epithelial cells and stromal connective tissue cells. 


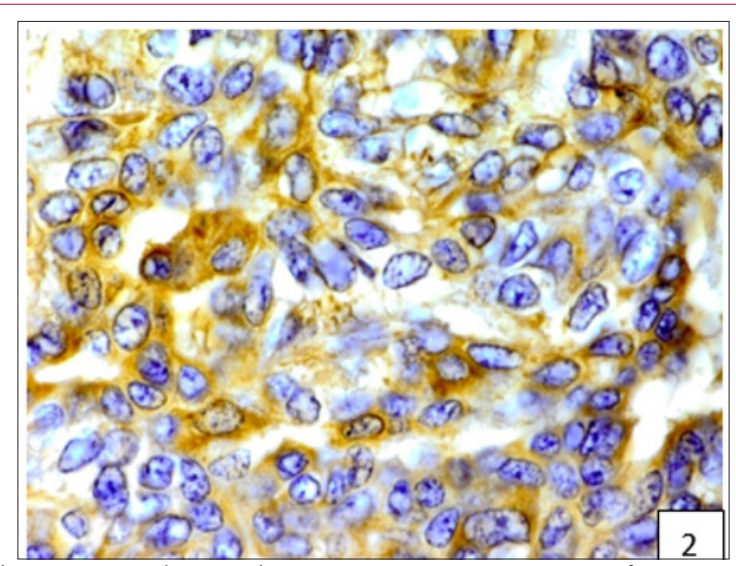

Figure 2: Diffuse and variable membranous and cytoplasmic immunoreactivity of BCRP was observed in cancerous epithelial cells and stromal connective tissue cells.

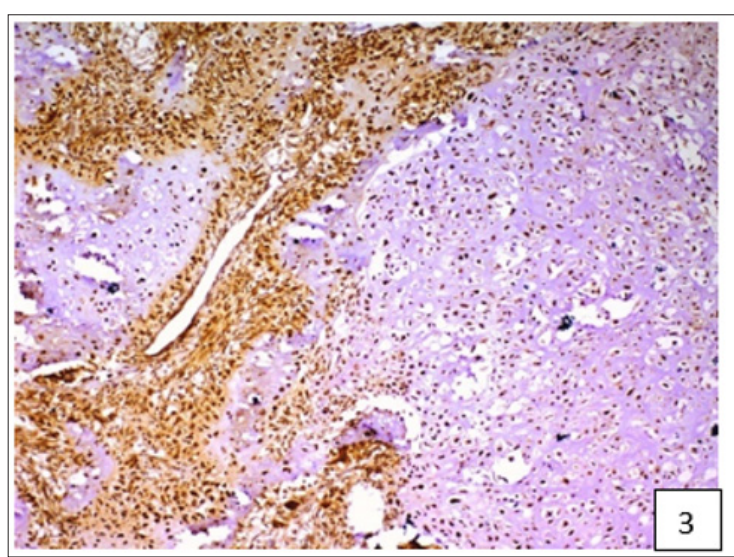

Figure 3: Diffuse and variable membranous and cytoplasmic immunoreactivity of BCRP was observed in cancerous epithelial cells and stromal connective tissue cells.

The average staining index of BCRP was 6.9, 7.75 and 7.92 in grade 1, 2 and 3 tumours, respectively (Figure 4). High expression of BCRP was observed in undifferentiated as compared to the well differentiated CMT cases. The average staining index of BCRP immunoreactivity in the cases of mammary sarcoma, carcinoma and carcinosarcoma in the present study was $6.28,7.57$, and 8.2, respectively (Figure 5). Variable cytoplasmic and membranous immunoreactivity of MDR1 was observed in the epithelial cells, immature connective tissue and EMT in all the 53 cases of CMT (Figures 6-7). A weak MDR1 reactivity in immature connective tissue was noted in comparison to its no reactivity in mature connective tissue (Figure 8). In addition, blood vessel endothelium, ductular epithelium and tumour emboli showed positive immunoreactivity for MDR1. On the basis of staining intensity, 18 cases revealed weak $(+), 24$ cases moderate $(++)$ and 11 cases strong (+++) immunoreaction.

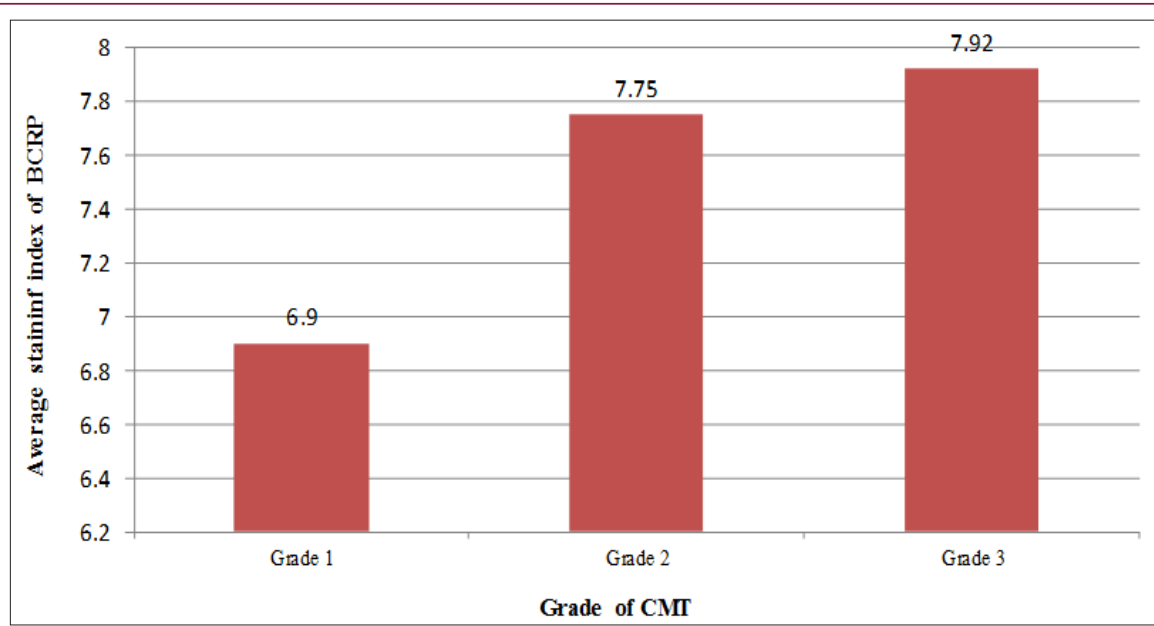

Figure 4: Immunohistochemical expression of BCRP according to the grade of CMT.

Cite this article: Naresh K S, Manoj K, Kuldip G, Amarjit S. Immunolocalization and Cellular Expression af Key Abc Transporter Proteins and Their Correlation with the Grades and Subtypes of Canine Mammary Tumour. Biomed J Sci\&Tech Res 7(3)- 2018. BJSTR. MS.ID.001502. DOI: 10.26717/ BJSTR.2018.07.001502. 


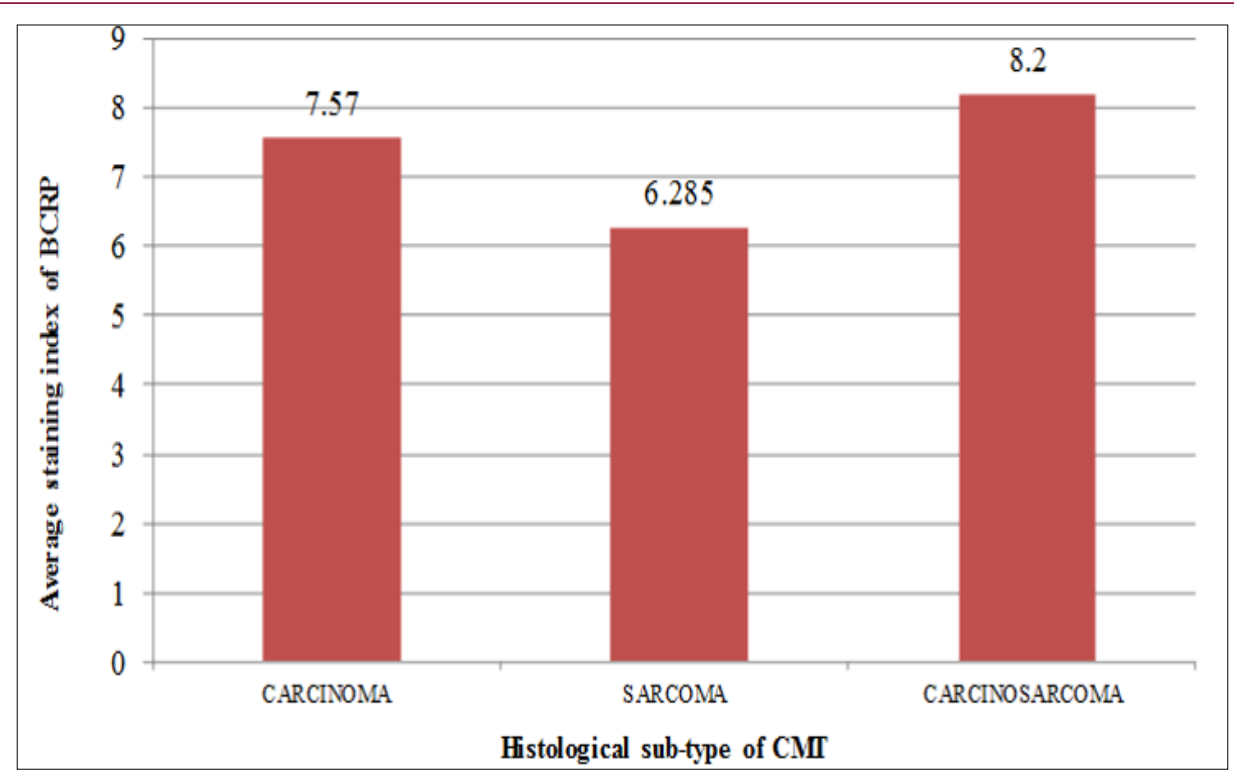

Figure 5: Immunohistochemical expression of BCRP according to histological sub-type.

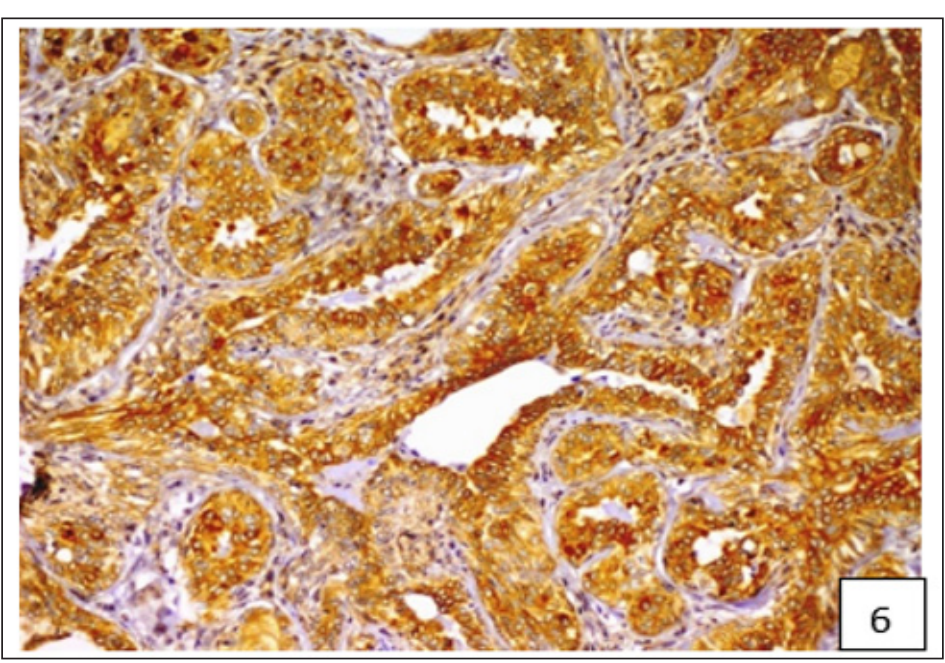

Figure 6: Variable cytoplasmic and membranous immunoreactivity of MDR1 was observed in the epithelial cells, immature connective tissue and EMT in all the 53 cases of CMT.

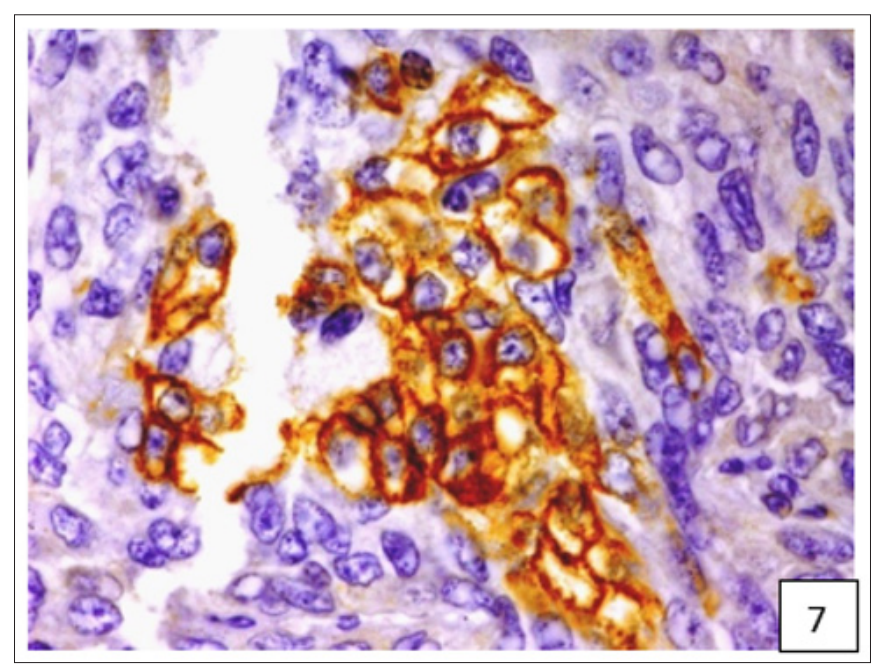

Figure 7: Variable cytoplasmic and membranous immunoreactivity of MDR1 was observed in the epithelial cells, immature connective tissue and EMT in all the 53 cases of CMT. 


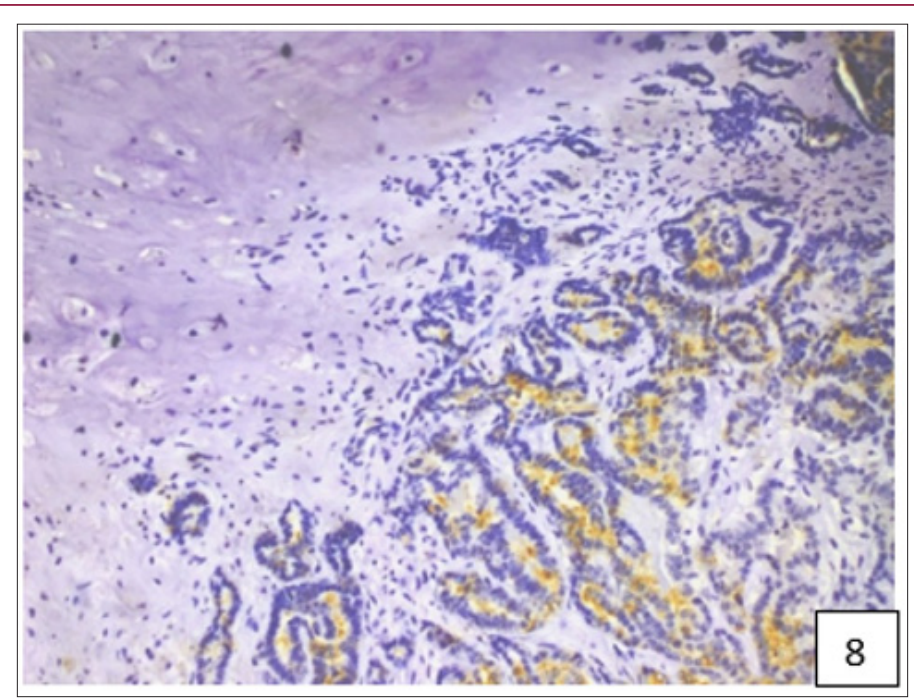

Figure 8: A weak MDR1 reactivity in immature connective tissue was noted in comparison to its no reactivity in mature connective tissue.

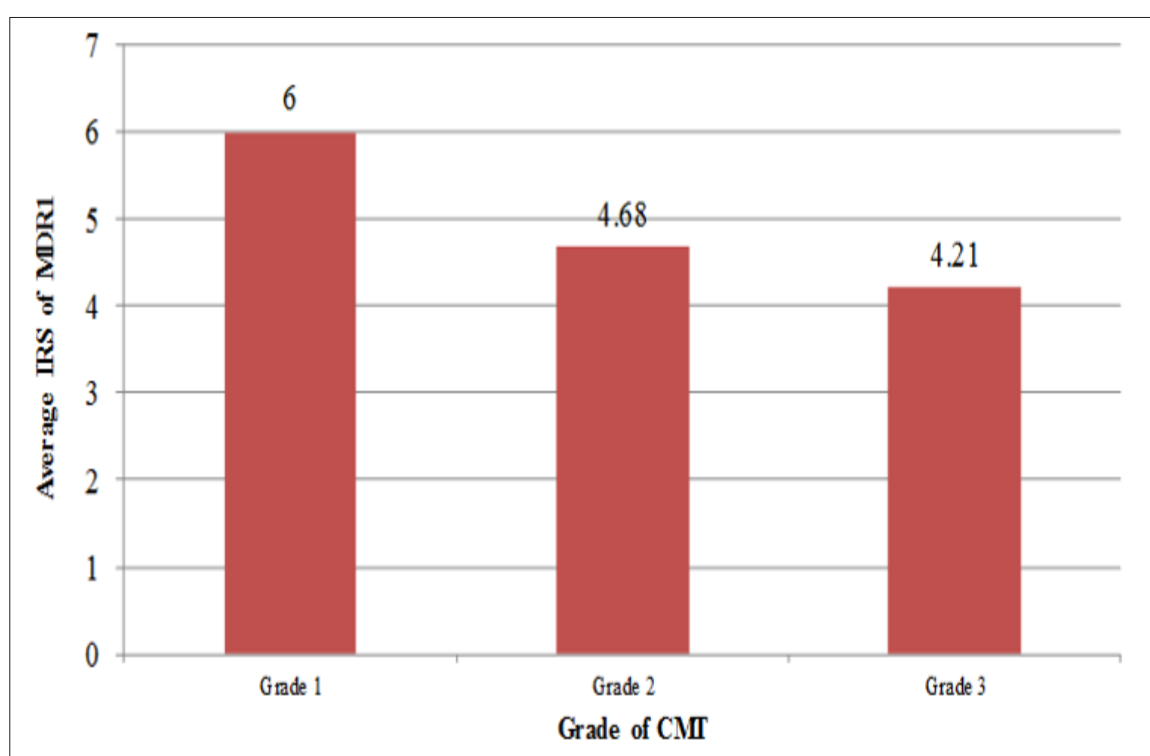

Figure 9: Immunohistochemical expression of MDR1 according to the grade of CMT.

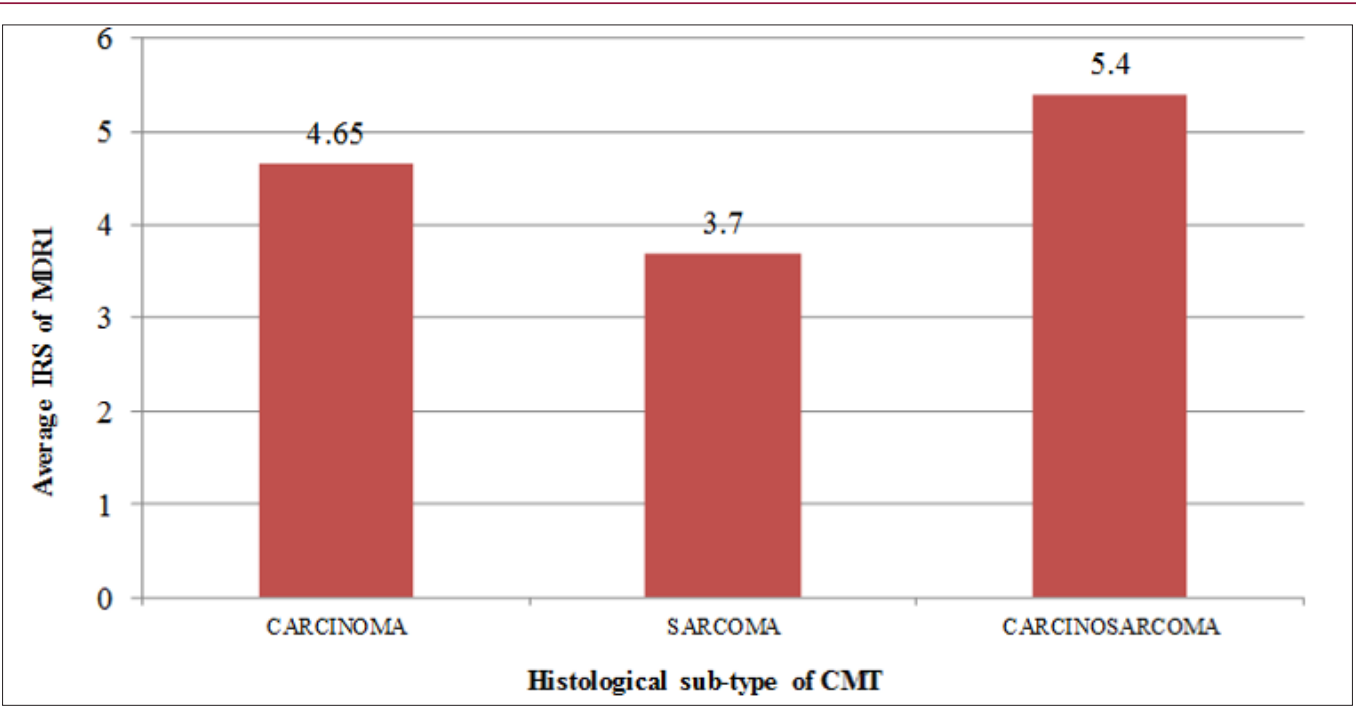

Figure 10: Immunohistochemical expression of MDR1 according to histological sub-type.

Cite this article: Naresh K S, Manoj K, Kuldip G, Amarjit S. Immunolocalization and Cellular Expression af Key Abc Transporter Proteins and 


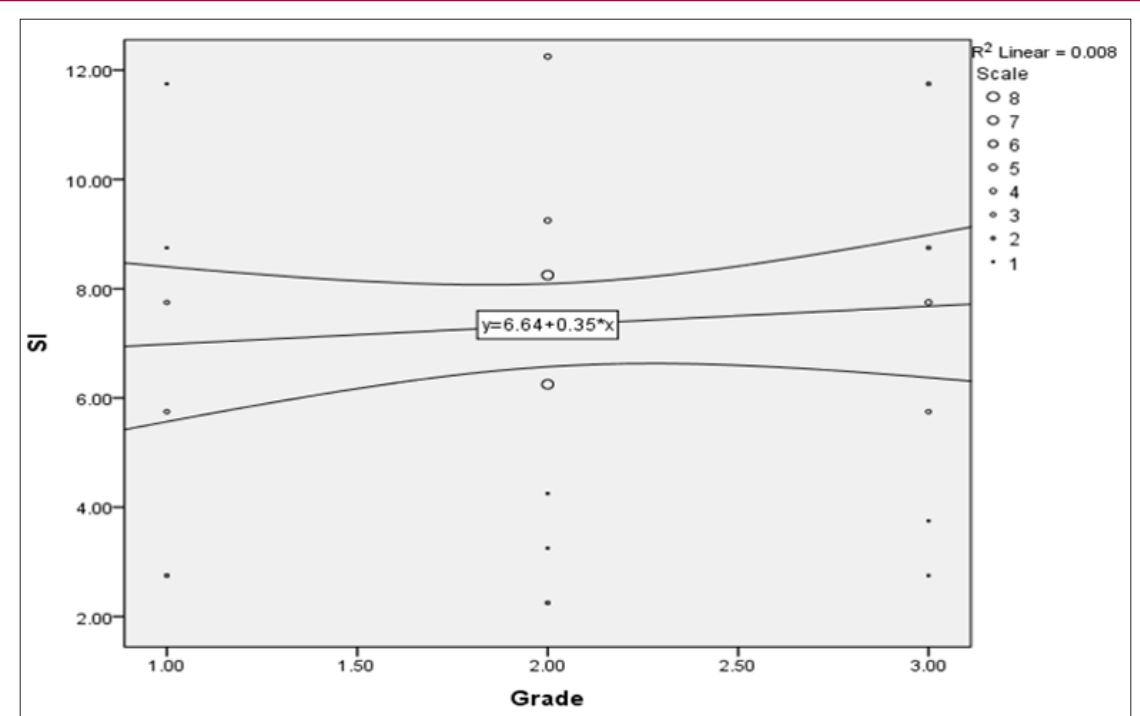

Figure 11: Correlation between BCRP expression and the grade of CMT.

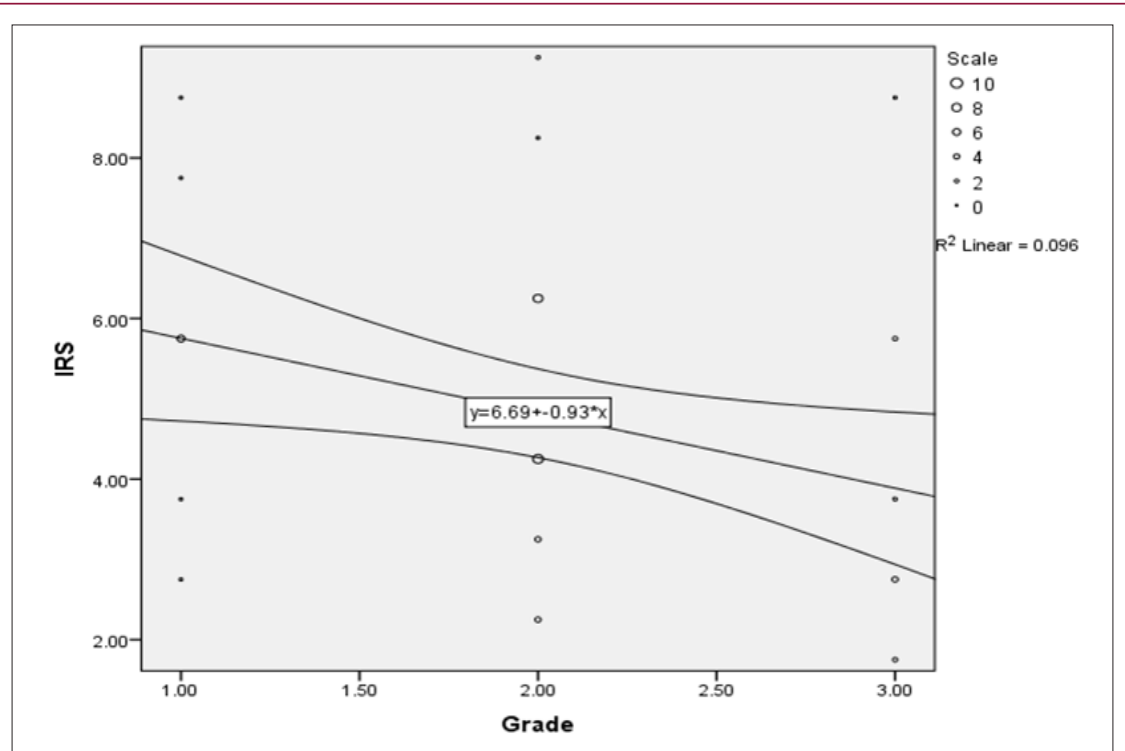

Figure 12: Correlation between MDR1 expression and the grade of CMT.

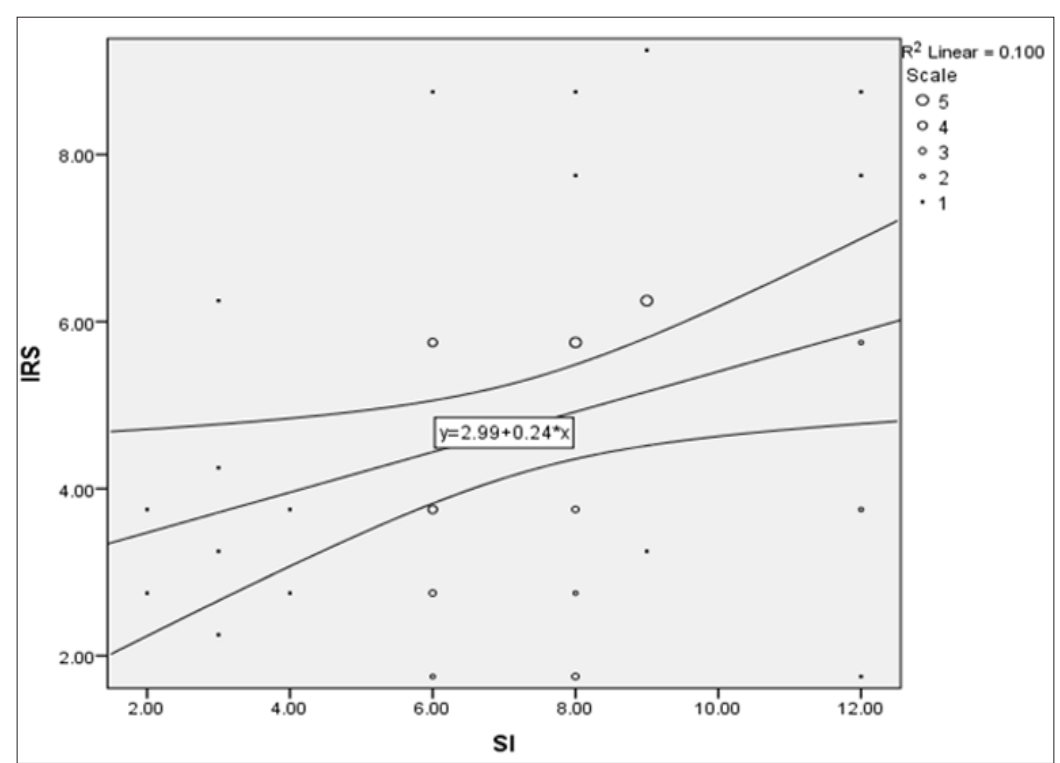

Figure 13: Correlation between expression of BCRP and MDR1. 
The average IRS of MDR1 was 6.0, 4.68 and 4.21 in grade 1, 2 and 3 tumours (Figure 9). The average staining index of MDR1 immunoreactivity in the cases of mammary sarcoma, carcinoma and carcinosarcoma in the present study was 3.7, 4.65, and 5.4, respectively (Figure 10). Spearman's correlation analysis revealed a low positive, non-significant correlation between BCRP expression and grade of CMT ( $\mathrm{r}=0.089)$ (Figure 11). On the other hand, a statistically significant and an inverse correlation between MDR1 expression and grade of CMT was observed ( $\mathrm{r}=$ -0.336; $\mathrm{p}<0.05$ ) (Figure 12). A moderate positive and significant correlation was observed between the staining index of BCRP and the immunoreactive score of MDR1 ( $r=0.332 ; \mathrm{p}<0.05)$ (Figure 13).

\section{Discussion}

Breast cancer resistance protein (BCRP), or ABCG2, is a member of the G subfamily of the ATP-binding cassette (ABC) efflux transporter superfamily, which is regarded as the most important member that induces multi-drug resistance [17-18]. In the present study, BCRP immunoreactivity was detected in all the 53 cases of CMT and was detected in the cytomembranes and cytoplasm, as reported earlier [18]. The human breast cancer studies also indicated a moderately high BCRP expression [19-20], but lower than that in the present study. In addition, in the present study, the immunoreactivity of BCRP was also observed in ductular epithelial cells, connective tissue, tumour emboli, endothelium and blood vessel wall. In the present study, a positive correlation was detected between BCRP expression and grade of the malignant CMT. Similarly, a positive correlation between expression of BCRP and grade of the tumour, indicated that an increase in the tumour malignancy was associated with the increase in the expression of BCRP [18]. On the contrary, studies on breast cancer suggested that BCRP expression was relatively low and did not appear to correlate with clinical outcome or grade [21-22].

However a significant correlation between BCRP and HER-2 expression, lymph node metastasis, and clinical stage in invasive ductal breast cancer had been reported [17]. BCRP not only played a role in drug-resistance but also could be regarded as a novel potential bio-marker for predicting the biological behavior, clinical progression, prognosis and effectiveness of chemotherapy in breast cancer. The expression of BCRP in connective tissue, tumour emboli and blood vessels in CMT seems to have been recorded for first time and needs further attention. MDR1 (P-gp) is a $170 \mathrm{kd}$ transmembrane protein that acts as an ATP-dependent efflux pump for lipotropic compounds out of cells and mediates multidrug tumour resistance [23]. In the present study, the immunoreactivity of MDR1 was observed in all the 53 cases of CMT. The immunoreactivity of MDR1 was observed in the cytoplasm and cytomembranes of the epithelial cells as reported earlier in breast cancer [16]. The immunoreactivity was also observed in the immature connective tissue. The observation regarding weak BCRP expression in connective tissue was augmented by similar MDR1 expression in CMT cases.

In contrast to our findings, no immunoreactivity for MDR1, in mesenchymal cells of CMT, was observed by earlier workers [23]. In addition, the immunoreactivity of MDR1 was also detected in vascular endothelium and tumour emboli. In the present study, a negative correlation between MDR1 expression and grade of CMT was found. Similarly, an inverse correlation between MDR1 and grade of CMT has been documented previously [24]. Therefore, MDR1 expression might be associated with favourable prognosis, which may be due to the fact that as the mammary tumours progress gradually from a lower to a higher grade, the expression of MDR1 might diminish if chemotherapy had not been used [2425]. Inhibition of MDR1 is an interesting approach to reverse inherent or acquired resistance to critical cytotoxic compounds for the treatment of breast cancer [26]. It was also demonstrated that targeting the MDR1 resistance pathway using siRNA was efficient at restoring chemosensitivity towards anticancer agents like doxorubicin and methotrexate. Similarly, MDR1 RNA interference was found to be effective for the treatment of drug-resistant cancer [27]. Previously, the role of $\mathrm{ABC}$ transporters in drug resistance against canine lymphomas [28, 29] and melanomas [30] and mammary cancer cell lines [31] has been incriminated.

\section{Conclusion}

The present study advocates the role of two major ATP-binding cassette (ABC) transporters viz. BCRP and MDR1 in CMT, which may have future therapeutic implications, particularly considering its role in comparative oncology as naturally occurring animal model for human breast cancer. These proteins were mainly immunolocalized in the cytomembranes of cancer cells and their expression was found to vary among cancer subtypes and grades, which could be a subject of discussion and further studies.

\section{Acknowledgement}

The authors are thankful to the Director of Research, GADVASU, Ludhiana, Punjab, India, for providing the necessary facilities to carry out the research.

\section{References}

1. Rezia A, Tavasoli A, Bahonar A, Mehrazma M (2009) Grading in canine mammary gland carcinoma. Journal of Biological Sciences 9: 333-338.

2. Gupta K, Sood NK (2012) Pathological and immunohistochemical studies on rare cases of primary extra-genital transmissible venereal tumours in the mammary gland. Veterinarni Medicina 57: 198-206.

3. Gupta K, Sood NK, Uppal SK, Mohindroo J, Mahajan S, et al. (2012) Epidemiological Studies on Canine Mammary Tumour and its Relevance for Breast Cancer Studies. IOSR Journal of Pharmacy 2: 322-33.

4. Gautam S, Sood NK, Gupta K (2014) Aberrant cytoplasmic accumulation of retinoblastoma protein in basal cells may lead to increased survival in malignant canine mammary tumours. Veterinarni Medicina 59: 76-80.

5. Misdorp W (2002) Tumours of the mammary gland in Tumours in domestic animals ( $4^{\text {th }}$ edn.)., Meuten DJ (Eds.) (Iowa: Iowa State Press) pp. 575-606.

6. Paoloni M, Khanna C (2008) Translation of new cancer treatments from pet dogs to humans. Nature Reviews Cancer 8: 147-56.

7. Gordon I, Paoloni M, Mazcko C, Khanna C (2009) The comparative oncology trials consortium: using spontaneously occurring cancers in dogs to inform the cancer drug development pathway. PLoS Medicine 6 (10): e1000161.

8. Muhammadnejad A, Keyhani E, Mortazavi P, Behjati F, Haghdoost IS, et al. (2012) Overexpression of HER-2/neu in malignant mammary tumors; translation of clinicopathological features from dog to human. Asian Pacific Journal of Cancer Prevention 13: 6415-6421. 
9. Stratmann N, Failing K, Richter A, Wehrend A (2008) Mammary tumor recurrence in bitches after regional mastectomy. Veterinary Surgery 37: 82-86.

10. Khan AM, Rampal S, Sood NK (2018) Effect of levofloxacin, pazufloxacin, enrofloxacin, and meloxicam on the immunolocalization of ABCG2 transporter protein in rabbit retina. Environmental Science and Pollution Research 25(9): 8853-8860.

11. Mo W, Zhang JT (2012) Human ABCG2: structure, function, and its role in multidrug resistance. International Journal of Biochemistry and Molecular Biology 3: 1-27.

12. Kim B, Fatayer H, Hanby AM, Horgan K, Perry SL, et al. (2013) Neoadjuvant chemotherapy induces expression levels of breast cancer resistance protein that predict disease free survival in breast cancer. 8(5): e62766.

13. Luna LG (1968) Manual of Histologic Methods of the Armed Forces Institute of Pathology. Mc Graw-Hill, New York, USA.

14. Misdorp W, Else EW, Hellmen E, Lipscomb TP (1999) Histological classification of mammary tumours of the dog and cat in WHO international histological classification of tumours of domestic animals.

15. Goldschmidt M, Pena L, Rasotto R, Zappulli V (2011) Classification and grading of canine mammary tumors. Veterinary Pathology 48: 117-131.

16. Surowiak P, Materna V, Matkowski R, Szczuraszek K, Kornafel J, et al. (2005) Relationship between the expression of cyclooxygenase 2 and MDR1/P-glycoprotein in invasive breast cancers and their prognostic significance. Breast Cancer Research 7: 862-870.

17. Xiang L, Su P, Xia S, Liu Z, Wang Y, et al. (2011) ABCG2 is associated with HER-2 expression, lymph node metastasis and clinical stage in breast invasive ductal carcinoma. Diagnostic Pathology 6: 90.

18. Nowak M, Madej JA, Dziegiel P (2009) Expression of breast cancer resistance protein (BCRP-1) in canine mammary adenocarcinomas and adenomas. In vivo 23(5): 705-710.

19. Maliepaard M, Scheffer GL, Faneyte IF, Van Gastelen MA, Pijnenborg AC, et al. (2001) Subcellular localization and distribution of the breast cancer resistance protein transporter in normal human tissues. Cancer Research 61(8): 3458-3468.

20. Park S, Shimizu C, Shimoyama T, Takeda M, Ando M, et al. (2006) Gene expression profiling of ATP-binding cassette $(\mathrm{ABC})$ transporters as a predictor of the pathologic response to neoadjuvant chemotherapy in breast cancer patients. Breast Cancer Research and Treatment 99: 9-17.
21. Kanzaki A, Toi M, Nakayama K, Bando H, Mutoh M, et al. (2001) Expression of multidrug resistance related transporters inhuman breast carcinoma. Japanese Journal of Cancer Research 92: 452-458.

22. Faneyte IF, Kristel PM, Maliepaard M, Scheffer GL, Scheper RJ, et al. (2002) Expression of the breast cancer resistance protein in breast cancer. Clinical Cancer Research 8: 1068-1074.

23. Suzuki T, Wangnaitham S, Rungsipipat A (2008) Expression of P-glycoprotein (P-gp) and multidrug resistance associated protein 1 (MRP1) in canine mammary tumours. Proceedings of the $15^{\text {th }}$ Congress of FAVA FAVA -OIE Joint Symposium on Emerging Diseases.

24. Kim NH, Hwang YH, Im KS, Kim JH, Chon SK, et al. (2012) P-glycoprotein expression in canine mammary gland tumours related with myoepithelial cells. Research in Veterinary Science 93: 1346-1352.

25. Sorenmo KU, Kristiansen VM, Cofone MA, Shofer FS, Breen AM, et al. (2009) Canine mammary gland tumours; a histological continuum from benign to malignant; clinical and histopathological evidence. Veterinary and Comparative Oncology 7: 162-172.

26. Perez J, Bardin C, Rigal C, Anthony B, Rousseau R, et al. (2011) Anti-MDR1 siRNA restores chemosensitivity in chemoresistant breast carcinoma and osteosarcoma cell lines. Anticancer Research 31: 2813-2820.

27. Wu H, Hait WN, Yang JM (2003) Small interfering RNA-induced suppression of MDR1 (P-glycoprotein) restores sensitivity to multidrugresistant cancer cells. Cancer Research 63: 1515-1519.

28. Zandvliet M, Teske E (2015) Mechanisms of drug resistance in Veterinary Oncology- A Review with an emphasis on canine lymphoma. Veterinary Science 2: 150-184.

29. Tomiyasu H, Tsujimoto $H$ (2015) Comparative aspects of molecular mechanisms of drug resistance through $\mathrm{ABC}$ transporters and other related molecules in canine lymphoma. Veterinary Science 2: 185- 205.

30. Finotello R, Monne Rodriguez JM, Ramirez GA, Haines A, Ressel L, et al. (2016) Immunohistochemical expression of MDR1-Pgp 170 in canine cutaneous and oral melanomas: pattern of expression and association with tumour location and phenotype. Veterinary and Comparative Oncology 15: 1393-1402.

31. Pawłowski KM, Mucha J, Majchrzak K, Motyl T, Krol M (2013) Expression and role of PGP, BCRP, MRP1 and MRP3 in multidrug resistance of canine mammary cancer cells. BMC Veterinary Research 9: 119.

\section{ISSN: 2574-1241}

DOI: 10.26717/BJSTR.2018.07.001502

Dr. Naresh Kumar Sood. Biomed J Sci \& Tech Res

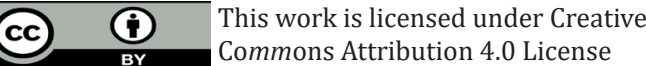

Submission Link: https://biomedres.us/submit-manuscript.php

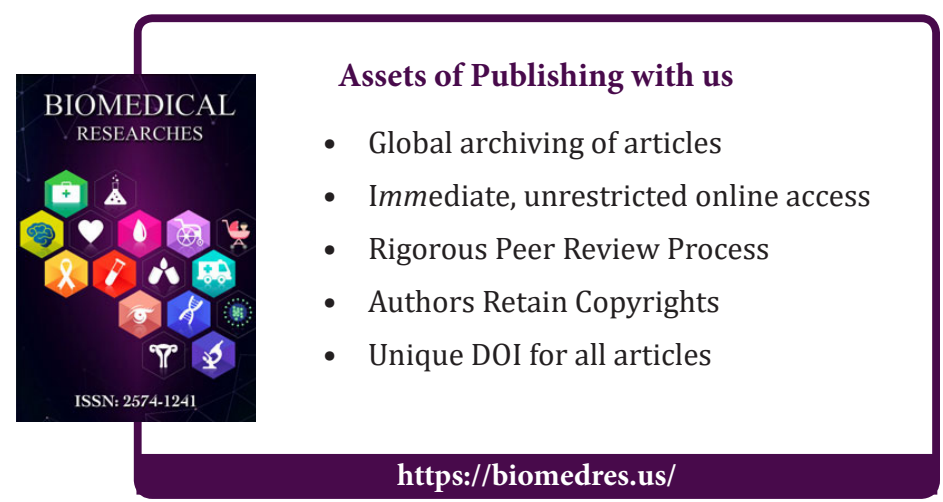

Cite this article: Naresh K S, Manoj K, Kuldip G, Amarjit S. Immunolocalization and Cellular Expression af Key Abc Transporter Proteins and 